Journal of Health Science
(Jurnal Ilmu Kesehatan)

\title{
Pengaruh Edukasi Senam Kaki Diabetes Mellitus Berbahasa Tetum Terhadap Sirkulasi Ekstremitas Bawah Dan Kadar Gula Darah Sewaktu Di Centru Saude Comoro, Dili, Timor Leste.
}

\author{
Carmelita Barros ${ }^{1}$, Fitri Arofiati ${ }^{2}$ \\ 1'Instituto Ciência Da Saúde (ICS) Dili, Timor Leste. \\ ${ }^{2}$ Magister Keperawatan, Program Pasca Sarjana,Universitas Muhammadiyah Yogyakarta. \\ 1carmelita barros@yahoo.com*,2arofiatifitri@gmail.com \\ *Corresponding author
}

\begin{tabular}{ll}
\hline Informasi artikel & ABSTRAK \\
\hline Received: 20-04-2020 & Diabetes mellitus (DM) di negara Indonesia lebih dikenal dengan istilah \\
Revised: 27-05-2020 & kencing manis dan di negara Timor Leste DM dikenal dengan istilah Ra'an \\
Accepted:30-05-2020 & Midar telah menjadi masalah kesehatan yang sangat serius, dan penyakit \\
& endokrin yang paling banyak dijumpai. Diabetes mellitus merupakan salah \\
& satu penyakit degeneratif yang di tandai dengan ganguan metabolik atau \\
Kata kunci: & kerusakan pankreas sehingga pankreas tidak mampu untuk memproduksi \\
Stunting & cukup insulin dengan maksimal sehingga dapat menyebabkan kekurangan \\
ibu & insulin didalam tubuh baik absolut maupun relatif dapat terjadi \\
Sosial & peningkatan kadar gula di dalam darah atau hiperglikemia. Metode \\
Demografi & penelitian : mengunakan metode Pra-Eksperiment. Populasi semua pasien \\
Toddler & diabetes mellitus yang dating berobat di Centru Saude Comoro dengan \\
& jumlah 100 orang, sampel 28 orang, teknik sampel: random simple, \\
& pengumpulan data:Pemeriksaan kadar gula darah, sirkulasi darah, uji \\
& statistik:Wilcoxon Test. Hasil penelitian : responden sebagian besar yang \\
& sirkulasi darahnya baik pre-test 15 orang (53,6\%) dan post test 18 orang \\
& (64,3\%). Hasil uji statistic mengunakan Wilcoxon Signed Rank Test \\
& mendapatkan nilai sirkulasi darah 0,005 dan kadar gula darah sewaktu \\
& $0,000$. Kesimpulan : ada Pengaruh Edukasi Senam Kaki Diabetes Melitus \\
& Berbahasa Tetun Terhadap Sirkulasi Ekstermitas Bawah dan Kadar Gula \\
& Darah Sewaktu Di Centru Saude Comoro, Dili, Timor Leste.
\end{tabular}

Key word:

Stunting

Mother's

Social

demography

toddler

\begin{abstract}
Diabetes mellitus (DM) in Indonesia is better known as diabetes and in Timor Leste DM known as Ra'an Midar has become a very serious health problem, and is the most common endocrine disease. Diabetes mellitus is a degenerative disease that is characterized by metabolic disorders or pancreatic damage so that the pancreas is unable to produce enough insulin to the maximum so that it can cause insulin deficiency in the body both absolute and relative can increase blood sugar levels or hyperglycemia. Method : using the Pre-Experiment method. Independent variable: Education of Tetum Language Diabetes Foot Gymnastics Education, dependent variable: Circulation of Lower Extremity and Blood Sugar Level at a Time. Population 100 people, sample 28 people, sample technique: simple random, data collection: Examination of blood sugar levels, blood circulation, statistical tests: Wilcoxon Test. Most respondents who had good blood circulation were 15 pre-test (53.6\%) and 18 post-test (64.3\%). The statistical test results using the Wilcoxon Signed Rank Test get a blood circulation value of 0.005 and blood sugar levels when 0,000. Conclusion: Conclusion there is the influence of Education on Tetun Language Diabetes Foot Gymnastics on Lower Extracurricular Circulation and Blood Sugar Levels At the Saude Comoro Center, Dili, Timor Leste.
\end{abstract}




\section{PENDAHULUAN}

Diabetes mellitus (DM) di negara Indonesia lebih dikenal dengan istilah kencing manis dan di negara Timor Leste DM dikenal dengan istilah $\mathrm{Ra}^{\prime} a n$ Midar telah menjadi masalah kesehatan yang sangat serius, dan penyakit endokrin yang paling banyak dijumpai. Diabetes mellitus merupakan salah satu penyakit degeneratif yang di tandai dengan ganguan metabolik atau kerusakan pankreas sehingga pankreas tidak mampu untuk memproduksi cukup insulin dengan maksimal sehingga dapat menyebabkan kekurangan insulin didalam tubuh baik absolut maupun relatif dapat terjadi peningkatan kadar gula di dalam darah atau hiperglikemia. (KEMENKES RI, 2013)

Penderita Diabetes Mellitus dari tahun ke tahun mengalami peningkatan menurut Internasional Diabetes Federation (IDF), penduduk dunia yang menderita Diabetes Mellitus sudah mencapai sekitar 197 juta jiwa, dan dengan angka kematian sekitar 3,2 juta orang. WHO (World Health Organization,) menyatakan bahwa Indonesia menempati urutan keenam di dunia sebagai negara yang jumlah penderita Diabetes Mellitus terbanyak setelah India, China, Jepang, Uni Soviet dan Brasil. Pada tahun 2016 diperkirakan 422 juta orang menderita DM lebih tinggi dibandingkan pada tahun 2007 sekitar 108 juta orang, diperkirakan pada tahun 2035 jumlah angka tersebut akan meningkat menjadi 592 juta orang yang terkena penyakit diabetes mellitus. Dari 422 juta tersebut dari 175 juta yang belum di diagnostik secara maksimal, prevalensi penyakit DM di Indonesia sebanyak 209.319 orang (PERKENI, 2014). Di Timor Leste terdapat 2690 orang yang menderita penyakit Diabetes Melitus Dari 2016-2017 (Buku Register dinas Kesehatan Dili Timor Leste) data dari Centru Saude Comoro dari bulan Januari sampai bulan Agustus 2018 terdapat 100 orang yang menderita penyakit DM (Buku register Puskesmas Comoro Dili Timor Leste, 2018).

Diabetes Mellitus tidak dapat disembuhkan tetapi kadar gula darah bisa dikendalikan melalui diet, olahraga dan mengkomsumsi obat-obatan. Kriteria nilai gula darah dikatakan baik, jika gula darah puasa $80-<100 \mathrm{mg} / \mathrm{dL}$, gula darah 2 jam setelah makan 80-144 mg/dL, A1C <6,5\%, kolesterol total $<200 \mathrm{mg} / \mathrm{dL}$, trigliserida $<150 \mathrm{mg} / \mathrm{dL}$, IMT 18,5- 22,9 kg/m2 dan tekanan darah $<130 / 80 \quad$ mmHg3 International Diabetes Federation (IDF).

Akibat dari kadar sirkulasi darah yang tidak terkontrol dengan baik maka dapat menyebabkan terjadinya komplikasi berbagai penyakit seperti hipertensi, jantung koroner, stroke, mata, syaraf, dan luka gangren. Hal ini disebabkan karena penderita diabetes mudah terkena infeksi, penderita dengan glukosa tinggi memudahkan perkembangbiakan kuman atau bakteri. Apa bila kadar glukosa darah di dalam darah meningkat maka akan mempengaruhi besar terhadap pasien yang menderita penyakit DM (Arja, 2000). Faktor yang dapat menyebabkan terjadinya penyakit diabetes mellitus adalah neuropati, tidak mengontrolkan kadar gula darah dengan baik, obesitas, pemakaian obat-obatan tertentu, (hiperglikemi berkepanjangan dapat menyebabkan hiperglisolia kronik yang merubah homeostasis biokimiawi sel dalam tubuh kemudian dapat berpotensi untuk terjadinya komplikasi DM. Umur di atas 50 tahun berisiko tinggi untuk terkena penyakit DM karena pada umur tersebut fungsi tubuh secara fisiologis mengalami penurunan, hal ini karena adanya penurunan sekresi insulin sehingga kemampuan fungsi tubuh terhadap pengendalian glukosa yang berlebih tidak optimal (Rondhanto, 2011).

Penggunaan alas kaki tidak tepat pada pasien DM sangat rentang terjadi luka, karena adanya neuropati diabetik dimana pasien DM mengalami penurunan indera perasa, maka dari itu penggunaan alas kaki yang tidak tepat akan mempermudah terjadinya luka karena penderita DM jika tertusuk benda tajam tidak terasa). Luka pada pasien DM yang tidak terkontrol, jika tidak dilakukan pengobatan akan menyebabkan timbulnya komplikasi yang membahayakan yaitu gangren (Sidani, 2009).

Diabetes mellitus dapat disebut dengan the silent killer karena pada penyakit ini dapat menyerang beberapa organ tubuh manusai dan mengakibatkan berbagai macam keluhan seperti poliuri, polidipsi, polifagia dan hipergikemia atau hipoglikemia. Penyakit ini tidak dapat disembuhkan tetapi glukosa darah dapat dikontrolkan melalui empat cara yaitu melakukan edukasi, pola diet yang teratur, olahraga dan mengkomsumsi obatobatan. Penyakit diabetes mellitus dapat 
mempengaruhi kualitas sumber daya manusia dan berdampak pada peningkatan biaya pengobatan yang cukup besar. Oleh karena itu diharapkan pada semua pihak baik pada pihak masyarakat maupunpemerintah, ikut serta secara aktif dalam penanggulangan kejadian penyakit DM, khususnya dalam upaya pencegahan (Rondhanto, 2011).masyarakat yang tingkat pengetahuan sangat rendah, dan ada masyarakat yang tinggal di daerah terpencil sehingga untuk menjangkau fasilitas kesehatan untuk mengontrolkan penyakitnya juga sangat minim sehingga terkadang mereka mengobatinya mengunakan obat tradisional seperti kepercayaan masyarakat Timor Leste bahwa dengan mengkomsumsi daun Sirsak akan membantu menurunkan kadar gula darah dalam tubuh. Dan sampai saat ini pemerintah Timor Leste belum ada Penyakit diabetes mellitus yang terjadi di Negara Timor Leste (TL) sangat tinggi yaitu menduduki peringkat ke 5 di tingkat nasional dengan penyakit kronik tertinggi dari pada penyakit lainnya. Hal ini dikarenakan tingkat pengetahuan masyarakat Timor Leste tentang penyakit DM sangatlah minim sehingga mereka mengabaikan saja apa bila terkena penyakit DM, dan sampai saat ini juga pemerintah Timor Leste belum mempunyai program untuk memberantaskan penyakit DM tersebut sehingga dari tahun ke tahun prevalensi penyakit DM di Negara Timor Leste sangatlah tinggi pada tahun 2018 terdapat 2690 orang menderita penyakit DM.

Timor Leste merupakan daerah dengan penduduk yang berasal dari berbagai macam suku, yaitu suku Mambae, Suku tokodede, suku Fataluku, Suku Bunak Suku makasae dan suku lainnya. Percampuran budaya dapat membawa perubahan yang membaik yang mana penduduk tidak hanya berasal dari satu atau dua kelompok saja atau saling ketergantungan (Burke, 2015).

Menurut Safitri (2013) mengatakan bahwa kebudayaan merupakan salah satu faktor yang mempengaruhi terjadinya DM seperti budaya barat dan budaya timor. Secara umum budaya barat lebih pada kendali internal sedangkan budaya timor lebih pada kendali eksternal. Hal ini di buktikan dengan angka kejadian penyakit DM yang sangat tinggi di Dunia dan di Negara Timor Leste (IDF, 2013) di karenakan perubahan pola makan program untuk memberantaskan penyakit DM (Dinas Kesehatan Timor Leste, 2019). Tujuan melakukan penelitian ini untuk mengetahui sirkulasi ekstremitas bawah sebelum dan sesudah melakukan senam kaki dan menganalisis sirkulasi ekstremitas bawah dan kadar gula darah sewaktu sebelum dan sesudah melakukan senam kaki diabetes mellitus di Centru Saude Comoro.

pasien DM karena fungsi dari senama kaki adalah untuk memperlancarkan sirkulasi darah, memperkuat otot kecil, mencegah kelainan bentuk kaki, meningkatkan kekuatan otot betis dan paha, mengatasi keterbatasan gerak akan tetapi di Timor Leste belum ada perawat yang menerapkan senam kaki di rumah sakit atau puskesmas dan pengobatan pada pasien DM di Timor Leste sangatlah minim dikarenakan ada (mengkonsumsi makanan yang banyak mengandung kalori, lemak, gula dan natrium) dan gaya hidup (diet dan aktifitas fisik yang sangat menurun). Senam kaki sangatl penting untuk diterapkan pada

\section{METODOLOGI PENELITIAN}

Dalam penelitian ini merupakan jenis penelitian kuantitatif dengan pendekatan Pra-Eksperiment dengan rancangan one grup pretest-post test. Tujuan dari penelitian ini untuk mengetahui pengaruh edukasi senam kaki diabetes mellitus berbahasa tetun terhadap sirkulasi darah dan kadar gula darah sewaktu dengan mengunakan video senam kaki Diabetes mellitus. Sampel dalam penelitian ini adalah semua pasien yang dating berobat di Centru Saude Comoro sebanyak 28 orang. Peneliti menyiapkan Video senam kaki DM dan alat pemeriksaan sirkulasi darah dan alat pemeriksaan Kadar gula darah sewaktu sebagai alat pengumpulan data, Peneliti mendatangi responden di Centru Saude Comoro. Mendata responden sesuai kriteria inklusi yaitu pasien yang bersedia menjadi responden, pasien yang tidak mengalami ulcus diabetik, pasien yang koperatif dan komunikatif, pasien yang tidak mengalami gangguan fungsi kognitif dan gangguan jiwa, pasien DM yang berobat di Centru Saude Comoro. Sampel dengan wawancara secara langsung dan memberikan penjelasan mengenai maksud kedatangan serta berjanji merahasiakan data responden, Setelah responden mengikuti senam kaki DM dan melakukan pemeriksaan gula darah dan 
sirkulasi darah, peneliti menjelaskan fungsi senam kaki dan pemeriksaan sirkulasi darah, Setelah selesai data dikumpulkan dan diolah sesuai langkah-langkah uji hipotesis dimana memberikan intrepretasi data, dan diberikan pembahasan sesuai hasil analisa data yang didapatkan peneliti.

HASIL

Pemeriksaan Sirkulasi Darah Sebelum Dan Sesudah Melakukan Senam Kaki Diabetes Mellitus, Pengaruh Edukasi Senam Kaki Diabetes Mellitus Berbahasa Tetun Terhadap Sirkulasi Darah Dan Kadar Gula Darah Sewaktu Sebelum Dan Sesudah Melakukan Senam Kaki.

\section{PEMBAHASAN}

1. Pemeriksaan sirkulasi darah sebelum dan sesudah melakukan senam kaki Diabates Melitus

2. Distribusi frekuensi pemeriksaan sirkulasi darah sebelum dan sesudah melakukan senam kaki diabetis di Centru Saude Comoro Dili Tahun 2019.

\begin{tabular}{llllll}
\hline Sirkulasi darah & \multicolumn{2}{c}{ Pre test } & \multicolumn{2}{c}{ Post test } \\
\cline { 3 - 6 } & & $\mathrm{N}$ & $\%$ & $\mathrm{~N}$ & $\%$ \\
\hline Baik & $\begin{array}{l}>1,4 \\
\mathrm{MHz}\end{array}$ & 15 & 53,6 & 18 & 64,3 \\
& $1 \mathrm{MHz}$ & 10 & 35,7 & 8 & 28,5 \\
\hline Kukup & 10,9 & 3 & 10,7 & 2 & 7,2 \\
\hline Total & & & & & \\
\hline
\end{tabular}

Berdasarkan hasil pemeriksaan sirkulasi darahsebelum melakukan senam kaki mendapatkan 15 (53,6\%) orang yang sirkulasi darahnya baik dan sesudah melakukan senam kaki mendapatkan 18 $(64,3 \%)$ orang yang sirkulasi darahnya meningkat yang terlihat pada tabel 4.2. Hasil penelitian yang dilakukan oleh Yunita (2011) menjelaskan bahwa responden sebelum melakukan latihan senam kaki aktifitas olahrag dalam sehari-hari, sehingga dapat menyebabkan vasodilatasi pada pembuluh darah untuk memperlancarkan sirkulasi darah didalam jaringan atau sel ditubuh terutama dibagian kaki. Pada pasien dengan DM jala kapiler sehingga akan terjadi peningkatan sirkulasi darah kaki dan penarikan glukosa dalam sel dan terjadi diabetis $60 \%$ responden mempunyai penyakit arteri ringan. Penelitian dari Flora (2013) menyatakan bahwa dengan memberikan latihan senam kaki diabetic pada penderita diabetes mellitus yang tidak mengalami komplikasi pada abagian kaki, penelitian ini sejalan dengan penelitian yang dilakukan oleh peneliti bahwa pada pasien dengan diabetes mellitus sebelum melakukan senam kaki sirkulasi darahnya menurun dan sesudah melakukan senam kaki sirkulais darahnya meningkat, Sehingga pada pasein dengan penyakit diabetes mellitus dianjurkan untuk melakukan senam kaki untuk memperlancarkan sirkulasi darah. Diabetes mellitus adalah gangguan metabolisme yang di tandai dengan hiperglikemia (kelebihan kadar gula didalam darah) yang berhubungan dengan abnormalitas metabolisme karbohidrat, lemak dan protein yang disebabkan oleh penurunan sekresi insulin atau keduanya dan dan menyebabkan komplikasi kronis mikrovasikuler, makrovasikuler dan neuropati (Nurarif dan Kusuma, 2015). Menurut Akhito (2010) komplikasi yang paling sering terjadi pada penderita diabetes mellitus adalah komplikasi luka gangrene pada bagian kaki. Adanya masalah kaki pada pasien DM karena kurang mengontrol kadar sirkulasi darah didalam tubuh sehingga glukosa darah banyak menumpuk dipembuluh darah, hal tersebut yang akan menyebabkan sirkulasi darah dijaringan kurang tidal lancar dibagian kaki dan menunjukkan tanda dan gejala seperti berkurangnya denyut nadi perifer dan neuropati perifer (pasien mengalami kebas atau kesemutan di kaki).

Menurut Soewondo (2017) sirkukasi arteri normal disebabkan karena mekanisme sirkulasi arteri normal akibat dilakukan senam kaki karena rangsangan dari aktifitas gerakan otot yang aktif pada saat melakukan gerakan senam kaki dan melakukan senam kaki melibatkan otototot utama (otot kaki) sehingga otot kaki berinteraksi secara teratur maka akan terjadi peningkatan laju metabolic pada otot yang aktif dan terjadi dilatasi pada arteriol maupun kapiler, menyebabkan jalaaliran darah normal pada kaki seperti aliran darah pada jaringan tubuh yang lain.

Menurut penelitian nilai rata-rata pada sirkulasi perifer sebelum 
memlakukan senam kaki diabetis mellitus menunjukkan sirkulasi darahnya terggangu karena responden selama menderita penyakit diabetes mellitus tidak melakukan aktifitas seperti senam kaki atau olah raga aerobik lainnya sehinnga pada saat melakukan pemeriksaan sirkulsi darahnya menunjukkan sirkulasi darahnya tergangu pada bagian kaki dan membuat pasien merasa cemas dan gelisah dengan kondisi tersebut. pada pasein dengan diabetes mellitus akan mengalami komplikasi yang sangat berat salah satunya adalah gangrene, pada pasien dengan penyakit diabetes mellitus dianjurkan untuk melakukan senam kaki agar memperlancarkan sirkulasi darah dan menghindari komplikasi ulkus diabetik.

3. Pengaruh edukasi senam kaki diebetse mellitus berbahasa tetun terhadap sirkulasi darah dan kadar gula darah sewaktu sebelum dan sesudah melakukan senam kaki

Distribusi frekuensi hasil uji statistik pengaruh edukasi senam kaki diabetes mellitus berbahasa tetum terhadap sirkulasi ekstremitas bawah dan kadar gula darah sewaktu di Centru Saude Comoro Dili Tahun 2019.

\begin{tabular}{lcccc}
\hline Variabel & $\begin{array}{c}\text { Pre- } \\
\text { test }\end{array}$ & $\begin{array}{l}\text { Pos- } \\
\text { test }\end{array}$ & $\mathrm{Z}$ & Sig \\
\hline $\begin{array}{l}\text { Sirkulasi } \\
\text { darah }\end{array}$ & 0,86 & 0,90 & -2.810 & 0,005 \\
\hline $\begin{array}{l}\text { Kadar } \\
\text { gula } \\
\text { darah }\end{array}$ & 205 & 197 & -4.492 & 0,000 \\
\hline
\end{tabular}

Berdasarkan hasil penelitian yang disajikan dalam gambar 4.2 menunjukkan bahwa sirkulasi darah meningkat dengan nilai presentasi 64,\% menunjukkan kadar gula darah menurun dengan niali presentasi berdasarkan tabel 4.3. 71,4\% Menunjukkan bahwa terdapat perbedaan nilai sirkulasi darah sebelum dan sedudah melakukan senam kaki dengan nilai 0,86 dan sesudah 0,90 dengan tingkat signifikan $p$ value $=0,005$, sedangkan pada nilai kadar gula darah sewaktu sebelum pada kaki adalah aliran darah yang dipompakan dari jantung keseluruh tubuh salah satunya adalah kaki yang dipengaruhi oleh tiga faktor utama yaitu viksositas (kekentalan darah), panjang pembuluh darah, dan diameter pembuluh melakukan senam kaki dengan niali 205 dan sesudah dilakukan senam kaki 197 dengan tingkat signifikan $p$ value $=0,000$.

Hasil penelitian ini memperkuat penelitian Wahyuni Arifin (2016) menjelaskan bahwa didapatkan rata-rata nilai Ankel Brachial Index (ABI) asien diabetes mellitus mengalami penurunan dengan nilai 0,6 yang didalam interprestasi kategori obstruksi sedang. Nilai ABI yang diperoleh pada saat skrining kaki adalah nilai yang kurang dimana keadaan ini pasien diabetes mellitus rata-rata mengalami gangguan pada pembuluh darah arteri dalam pembuluh darah perifer. Senam kaki yang dianjurkan pada pasien diabetes mellitus adalah senam aerobik yang artinya, senam kaki tersebut membutuhkan oksigen dan dapat membantu memperlancarkan sirkulasi darah, mmperkuatkan otot kecil kaki, mencegah terjadinya kelainan bentuk kaki yang dapat meningkatkan potensial luka gangren di bagian kaki, dan meningkatnya produksi insulin yang dapat dipakai dalam transportasi glukosa ke sel sehingga membantu menurunkan kadar glukosa dalam darah (Dewi, Sumarni, \& Sundari 2012).

Gerakan senam kaki yang dilakukan selama senam kaki diabetes mellitus sama halnya dengan melakukan pijatan kaki yang memberikan tekanan dan gerakan pada kaki untuk mempengaruhi hormone yaitu meningkatkan sekresi endorphrin yang berfungsi untuk menurunkan sakit, vasodilatasi pembuluh darah sehingga terjadi penurunan tekanan darah terutama tekanan sisolik brachialis yang berhubungan langsung dengan nilai Ankel Branchial Index (ABI). Senam kaki akan membantu tubuh menjadi rileks dan memperlancarkan peredaraan darah. Peredaraan darah yang lancar akibat digerakan dapat menstimulasi darah untuk mengantar oksigen dan gizi lebih banyak kedalam sel-sel tubuh, serta membantu membawa keluarkan racun lebih banyak (Hansneli, \& Novayelinda, 2012).

Hasil penelitian dari Agustianingsih (2013) memaparkan bahwa sirkulasi darah

darah. Diabetes mellitus adalah salah satu faktor yang mempengaruhi terhadap tekanan aliran darah karena faktor viksositas diakibatkan penumpukan kadar gula darah sedangkan kekentalan darah akan mengakibatkan terganggu aliran 
darah keseluruh tubuh dan bisa dapat menyebabkan penurunan perfusi ke jaringan tubuh.

Purnawati (2013) menjelaskan bahwa penyakit arteri perifer (PAP) terjadi penurunan sirkulasi perifer yang rendah sehingga dapat mencetuskan terjadinya ulkus dikubitus atau ulkus berulang. Hal ini terjadi karena penyebab dari ulkus sangat sulit untukk disembuhkan karena disebabkan oleh lemahnya nadi didorsalis pedisis atau tibia posterior pada salah satu kaki diabetes. Dengan latihan dapat mengurangi gejala nyeri pada ekstremitas bawah karena dengan PAP meningkatnya kapasitas latihan untuk mencegah atau mengurangi cederah fisik dan mengurangi terjadinya penyakit kardiovasikuler dan pembuluh darah.

Senam kaki pada pasien diabetes mellitus merupakan kegiatan atau latihan yang dilakukan oleh penderita diabetes mellitus untuk mencegah terjadi luka dan membantu memperlancarkan peredaraan darah dibagian kaki. Senam kaki dapat membantu memperbaiki sirkulasi darah dan memperkuat otot-otot kecil dan mencegah terjadinya kelainan pada bentuk kaki, meningkatkan kekuatan otot betis, otot paha dan juga mengatasi keterbatasan pada pergerakan sendi (Nurrahmani Kurniad, 2014).

Gerakan senam kaki juga dapat meregangan kaki (stretching). Stretching pada kaki diangap efektif melancarkan sirkulasi darah ke daerah kaki, meningkatnya kerja insulin dan melebarkan pembuluh darah dimana insulin bekerja sebagai penghambat proses lipolysis yaitu pengurayan trigliserida menjadi asam lemak dan gliserol, sehingga terjadi pengeluaran asam lemak yang berlebihan dari jaringan adipose ke dalam aliran darah untuk mengurangi resiko arterosklerosis, dapat meningkatkan aliran darah ke ekstremitas bawah dan berperan serta meningkatnya tekanan sistolik pada kaki (Yasa, Endang \& Bagiarta, 2013).

Peneliti menyimpulkan bahwa senam kaki diabetes mellitus yang akan dilakukan dengan rutin oleh responden akan berdampak baik pada nilai Ankle Brachial Index (ABI) yang akan terjadi pada setiap individu karena dengan melakukan gerakan pada senam kaki berguna untuk memperlancarkan sirkulasi darah dikaki dan mencegah komplikasi gangrene dan penyakit arteri perifer (PAP). Selain itu senam kaki ini dapat dilakukan dengan mudah karena hanya mengunakan kursi, Koran dan dapat dilakukan kapan saja dan diaman saja tampa menganggu aktifitas yang lain, tidak memerlukan biaya yang mahal, tidak mengeluargan energy yang banyak serta sangat bermanfat sekali bagi penderita diabetes mellitus.

\section{KESIMPULAN}

1) Nilai sirkulasi darah sebelum melakukan senam kaki menunjukan ada responden sirkulasi darahnya buruk atau menurun tetapi setelah dilakukan senam kaki nilai sirkulasi darahnya meningkat atau sirkulasi darahnya lacar.

2) Adapun Pengaruh Edukasi Senam Kaki Diabetes Melitus Berbahasa Tetun Terhadap Sirkulasi Ekstermitas Bawah dan Kadar Gula Darah Sewaktu

\section{SARAN}

1) Bagi pasien diabetes mellitus

Diharapkan agar pasien dengan penyakit diabetes mellitus rutin dalam melakukan senam kaki untuk memperlacarkan sirkulasi darahnya untuk mencegah terjadinya komplikasi.

2) Bagi keluarga

Agar anggota keluarga diharapakan memberikan dukungan keluarga secara emosional agar pasien mempunyai semangat untuk mengikuti senam dan melakukan pola diet yang baik untuk menurunkan kadar gula darah dan memperlancarkan sirkuasi darah.

\section{DAFTAR PUSTAKA}

Aalto, A.M, Anitti, U., dan Arja, R.A. 2000. Disease Related distress among insulintreante patients. Europen Jurna l of public Healten.https/watermark.si lverchair.com.

Adi Sucipto, (2014). Efektifitas Konseling Dalam Meningkatnya Kepatuhan Dan Pengendalian Gula Darah Pada Pasien DM tipe 2

Agus Suprijono. (2014). Cooperative Learning:Teori dan Aplikasi PAIKEM. Yogyakarta: Pustaka Pelajar. https://www.google.com/search.

Agustianningshi, dkk. 2013. Self Esteem Assesment in Patient with Type 2 
Diabetes. American Jurnal of Pharmtech Recearch. 2013. 6(6): 2249-3387.

http://www.ajprt.com/archive/volum e-6/december-2013-issue

Akhito, A.M., Antiti, U dan Arja R.A. 2010. Disease-related distress among insulin treated diabetic patient. Europen Jurnal of public health 10(1). https//watermark.silverchaie.com

Allen, Stabler, Kenjale, Ham, Annex. 2014. Diabetes status differentiates endothelial function and plasma nitrite response to exercise stress in peripheral atherial disease following supervised training, Journal of diabet es and its complications, http://search.proquest.com

Amin Huda Nurarif, S. (2015) APLIKASI Asuhan Keperawatan Berdasarkan Diagnosa Medis \& NANDA NIC-NOC. Yogyakarta: Media Action

American Health Association. 2012. Measurement and interpretation of the ankle brachial index: a scientific statement from the american heart association, Circulation, http://circ.ahajournals.

American Diabetes Association. 2014. Standar of medical care in diabetes, Diabetes Care, Volume 37, Supplement http://care.diabetesjournals.

Arja, s. (2000). akuntabilitas dan pengukuran kinerja pemerintah. jurnal akuntansi dan keuangan, vol 2 no 2 http://repo sitory.umy.ac.id/bitstream/handle/1 23456789/26025

Aziz, A. H., 2007. Metode PenelitianKeperawatan dan Teknik AnalisaData.Jakarta: Salemba Merdeka

Bagiantra, B., \& Oftedal. (2013). The relationship between clinical indicators, coping styles, perceivedsupport and diabetes-

article, Sport Med; http://search.proquest.com

Henrikson, J.E.,\& Nielsen, H. (2009). Blood glucose levels. Diakses 25 januari 2019 Dari http://www.netdoctor.co.uk/healthad vice/facts/diabetesblood sugar.htm.

International Diabetes Federation. IDF Diabetes Atlas 6th Edition 2016: related distress among adults with type 2 diabetes. Journal of adva nced nursing. http://eprints.ums.ac.i $\mathrm{d} / 56474$

Buku Register Dinas Kesehatan Dili Timor Leste (2019). Buku Register Puskesmas Comoro (2019)

Burke, J.M \& Hawks, J.H (2015).Keperawatan Medikal Bedah : Manajemen Klinis untuk Hasil yang Di harapkan.Edisi 8-Buku 2. Jakarta : Salemba Medik. http://repository.unissula.ac.id

Darwis, Y.dkk. (2005). Pedoman Pemeriksaan Laboratorium Untuk Penyakit DM. Departemen Kesehatan Indonesia. Jakarta

Diah Astutiningrum, Nurlaila . Efektivitas E dukasi Peer Group Terhadap Peruban Pengetahuan, Sikap Dan Ketrampilan Dalam Pencegahan Kanker Servik Di Kabupaten Kebumen herniyatun $h$ ttps://ejournal.stikesmuhgombong.ac. id/index.php/JIKK/article/view/54

Ending, Barati. 2013. The Healthe Belief Model and Self-Care Behavivors among Type 2 Diabetic Patientes. Iranian Jurnal of Diabetes And Obesity, Volume 6, Number 3. https://www.google.com /searc.

Flox \& Kilvert, (2010). Bersahabat dengan diabetes tipe 2. Penebar Plus. Jakarta

Flora, B, Rao S \& Sanal., 2013. The Effect of Perceived Stress and Family Functioning on People with Type2 Diabetes Mellitus. Journal of Clinical and Diagnostic Research.Vol. 7(12), pp. 2929-2931

Hansenline. D, Dendale. P, Loon. L.J.C, Meeusen. R. 2012. The impact of training modalities on the clinical benefits of exercise intervention in patients with cardiovascular disease risk or type 2 diabetes mellitus review

International Diabetes Federation; 2016. http://scholar.unand.ac.id

Irawan, H.Q. 2010. The Experence of Hypoglicaemia and strategies used for its management bay communitydwelling with diabetes mellitus: A systematic revieu. International Jurnal of Evidence Bosed Healthcare, 10(3:) 196180.https://doi.org.10.1111/i. 
Irwan. (2016). Epidemiologi Penyakit Tidak Menular. Yogyakarta : Deepublish

IT Dept. RSI Sultan Agung. 2010. Tak Ingin Amputasi Lakukan Senam Kaki, http://www.rsisultanagung.co.id.

JatinangorYulia Sofiatin, Rully M.A. Roesli . Kesiapan Masyarakat Dalam Melaksanakan Dan Memanfaatkan Posyandu Penyakit Tidak Menular Di Desa Cilayung Dan Cipacing, Kecamatan https://ejournal .unisba.ac.id/index.php/gmhc/article/ view

Kemenkes, R.I.2013. Pedoman surveilans penyakit tidak menular (p.2-5). Jakarta :Ditjem PTM

Leong L.P dan Shui G, 2014. An Investigation of Antioxidant Capacity of Fruits in Singapore Markets, Food Chemistr y,76: 69-75

http://repository.usu.ac.id/bitstream /handle/123456789/63854/Referenc e.pdf

Mahendra, KD.dkk (2008). Care Your Self Diabetes Mellitus. Penerbit Plus. Jakarta

Maulana, Heri, d.j, Promosi Kesehatan (Jakarta : Penerbit Buku Kedokteran EGC, 2009).

Nursalam. (2013) Konsep Dan Penerapan Metodologi Penelitian Ilmu Keperawatan. Jakarta: Selemba Medika.

Nursalam. 2008.Konsep Dan Penerapan Me todologi Penelitian Ilmu Keperawatan . Jakarta:Salemba Medika.

Nurarifin, K. 2015. Internet and Information Thecnology Use in treatment of Diabetes. International Jurnal of Clinical Practice.Suplement 41-46.

https://www.google.com/search

Nordqvist, C. (2004). What is blood sugar? What is blood glucose? Diakses 25 Januari 2019 dari http://www.medicalnewstoday.com/a rticles/249413.php

Oktaveni, (2011). Hubungan gaya hidup dengan insiden penyakit Diabetes Mellitus tipe 2 di poliklinik endokrin RSUD ZA Banda Aceh 2011. Banda Aceh: Universitas Syiah Kuala. file:/// c:/users/hewlett\%20packard/downlo ads/1591-2993-1-sm.pdf

Perkumpulan Endokrinologi Indonesia. 2011. Konsensu Pengelolaan Dan
Pencegahan Diabetes Mellitus Tipe 2 di Indonesia. Jakarta: PB. PERKENI.

Pearce C. EVELIN (2011) Anatomi Fisiologi Para Medis.

Purnawati, M.dkk. 2013. Factores Assosiated With High Stress Level in Adultus with Diabetes Mellitus Attending a Teriaty Diabetes Care Center, Chennai, Tamil Nadu, Indian Jurnal of Endocrinology and Metabolism 21(1):56-63.http ://www.nebi.nlm.nin.gov/pmc/articls /PMC5240082/.

Rondhianto. 2011. Pengaruh self care Management Education dalam DischargePlanning terhadap Self efficacy dan Self Care Behavuour Pasien Diabetes Mellitus Tipe 2 (Tesis). http://doi.org/10.2337/dc09.

Safitri, Nurmalia. 2013. Faktor Faktoryang Berhubungan Dengan Niat Untuk Me milih Pelayanan Rawat Inap Di Rumah Sakit Bogor Medical Center Tahun 2011. Tesis Universitas Indonesia Depok.

Sarifah, S. (2011)) Faktor-Faktor Yang Mempengaruhi Tingginya Kadar Gula Darah Pada Pasien DM Yang Menjalani Terapi DM Di Poliklinik Penyakit Dalam Rsup Dr. Sarjito Yogyakarta. Jurnal Kesehatan Professional Islam. Vol 7 di akses 25 Februari 2019.

Sidani, S.\& Fan, L. 2009. Effectiveness of Diabetes Self-management Education Intervention Elements: A.Metaanalysis. Canadian Jurnal of Diabetes Volume $33 \quad$ (1):p.18-26. https://www.google.com/search

Siti Aisah, Junaiti Sahar, Sutanto Priyo Hasto. Pengaruh Edukasi Kelompok Sebaya Terhadap Perubahan Perilaku Pencegahan Anemia Gizi Besi Pada WanitaUsia Subur Di Kota Semarang https://jurnal.unimus.ac.id/index.pp

Simamora, Bilson, 2008. Memenangkan Pasar dengan Pemasaran Efektif dan Profitabel, PT. Gramedia Pustaka Utama, Jakarta.

Sherwood. (2011). Fisiologi Manusia Dari Sel Ke Sistim. Edisis 6. EGC.Jakarta

Soegondo, dkk. (2009) Dukungan Keluarga Meningkatkan Kepatuhan Diet Pasien DM Di Ruang Rawat Inap Rs. Baptis 
Kediri. Jurnal STIKES. Vol 6, No. 1 di akses 26 Februari 2019

Soewondo, E dan Mehmet, K. 2017. Depresion Anxiety and Sress Scale (DASS):The Stdudy of Validity and Reability. Universal Jurnal of Educational Recearch 4(1):1-44 https://www.nebi.mln.nih.gov/pubm ed/26151640

Smeltzer, S.C., \& Bere, B.G (2009). Texbook Of Medical Surgical Nursing.

Smeltzer \& Bere, (2001). Buku Ajar Keperawatan Medikal Bedah (Bruner $\&$ Suddarth) Edisi 8 Vol.2. Penerbit: EGC, Jakarta

Soegondo, Sidartawan, Pradana Soewondo, Imam Subekti, ed. Penatalaksanaan Diabetes Melitus Terpadu. Jakarta: Balai Penerbit FKUI; 2004

Sugiyono. (2014). Metode Penelitian Pendidikan Pendekatan Kuantitatif, Kualitatif dan R\&D. Bandung: Alfabeta

Sulyono, J (2012). 6 Hari jago SPSS 17. Cakrawala, Yogyakarta

Sumarni, M dkk.2012. Factores Assosiated With High Stress Levels in Adults with Diabetes Mellitus Attending aTeriatry Diabetes care Cente, Chennani, Tami Nadu. Indian Jurnal of Endocrinologi and Metabolism 21(1): 56-63 https://digilib.esaunggul.ac.id/public /UEU-Undergraduate-4422

Sundari, R.T., 2012.Faktor faktor Risiko Ulk us Diabetika Pada Penderita Diabetes Melitus Studi Kasusdi RSUD Dr. Moew ardi Surakarta [dissertation].

Universitas Diponegoro.

https/www.com

Trisnawati, KS., Setyorogo, Soedijono. 2013. Faktor Risiko Kejadian Diabetes Mellitus Tipe 2 Di Puskesmas Kecamatan Cengkareng Jakarta Barat Tahun 2012. Jurnal Ilmiah Kesehatan. Vol 5 No. 1 : 6-11

Probosuseno.(2007). Mengatasi Isolasi Lanjut Usia. http//medicalzone.org. di-unduh tanggal 28 Juli 2019.

Wahyuni, A.C. (2016). Knowledge About Risk Factors, Symtoms And Complication Of Diabetes Among Adult In South India. India: Jurnal Community Medicine. Vol. 3, Iss. 9.

World Health Organization. Global Report on Diabetes. France: World Health Organization; 2016. http://scholar.unand.ac.id/33436/4
Yeni. Y., Salmiah, A., Erkadius. 2014. Penilaian Viabilitas Iskemia Usus Intra Operatif Dengan Angiografi Floureseince (Percobaan Eksperimental Pada Usus Halus Tikus Wistar). Artikel Penelitian. Majalah Kedokteran Andalas. No.1. Vol. 29: 27-39

Yustini, S.K dan Soedijono S., 2013. Faktor Risiko Kejadian Diabetes Melitus Tipe II Di Puskesmas Kecamatan Cengkareng Jakarta Barat Tahun2012. Jurnal Ilmiah Kesehatan, 5(1): pp. 6-11 http://repository.unimus.ac.id/1775

Yendi, Erol. 2014 An Individualized Education Programe With oEmpowement Approach: A Case Study. Internationla Jurnal of Caring Sciences 8(2):451-57

Yunitah., G., Muneeshwari, K. \& Khan, P. H., 2011. Recent Trends In Insulin Drug Delivery System. International Journal of Pharmaceutical Development \& Technology, 1(2), pp. 20-28 